\title{
VALIDASI DAN ANALISIS KADAR AKRILAMIDA PADA KOPI TUNGKAL DENGAN METODE KROMATOGRAFI CAIR KINERJA TINGGI (KCKT)
}

\author{
Harmita Swandi $^{1 *}$,Armini Hadriyati ${ }^{1}$, Mukhlis Sanuddin ${ }^{1}$ \\ ${ }^{1}$ Program Studi Farmasi, STIKES Harapan Ibu Jambi \\ *e-mail: Harmitaswandi@gmail.com
}

diterima:28 Januari 2020; direvisi: 2 Maret 2020; disetujui:27 Maret 2020

\begin{abstract}
ABSTRAK
Akrilamida merupakan senyawa kimia yang terdapat pada kopi yang disangrai pada suhu diatas $120^{\circ} \mathrm{C}$, berpotensi menyebabkan kanker pada manusia. Kopi yang digunakan merupakan hasil olahan rumahan di Desa Kecamatan Betara Kabupaten Tanjung Jabung Barat, Kuala Tungkal, Jambi. Tujuan dari penelitian ini untuk menentukan kandungan akrilamida kopi bubuk tradisional dengan metode kromatografi cair kinerja tinggi (KCKT). Fase gerak yang digunakan asetonitril : asam fosfat $(80: 20 \mathrm{v} / \mathrm{v})$, menggunakan kolom C18 atau oktadesil silica (ODS) dengan ukuran $250 \mathrm{~nm} \times 4,6 \mathrm{~mm}$, volume injeksi $20 \mu$, detektor Genesys 10S UV-Vis pada panjang gelombang $203 \mathrm{~nm}$. Akrilamida pada kopi bubuk terindentifikasi pada waktu retensi $(\mathrm{tR}) \pm 5,826$ menit. Metode ini terbukti valid dengan linearitas $\mathrm{y}=20717 \mathrm{x}+28752$, koefisien korelasi (r) $=0,998 \%$, batas deteksi 0,32109 ppm dan batas kuantitasi 1,07031 ppm, presisi dengan $\%$ SBR $<2 \%$. Kadar akrilamida dalam sampel kopi bubuk 1 sampai 4 berturut-turut adalah 72,065 $\mu \mathrm{g} / \mathrm{g}$ sampel (1), 66,922 $\mu \mathrm{g} / \mathrm{g}$ sampel (2), 60,215 $\mu \mathrm{g} / \mathrm{g}$ sampel (3) dan 61,422 $\mu \mathrm{g} / \mathrm{g}$ sampel (4). Dari keempat sampel kopi menunjukan bahwa kadar akrilamida masing-masing sampel melebihi batas aman konsumsi akrilamida yang dikeluarkan oleh FDA yaitu $2 \mu \mathrm{g} / \mathrm{g}$.
\end{abstract}

\section{Kata Kunci: Akrilamida, Kanker, KCKT, Kopi bubuk}

\section{VALIDATION AND ANALYSIS OF ACRYLICIDE LEVELS IN TUNGKAL COFFEE WITH HIGH PERFORMANCE LIQUID CHROMATOGRAPHY METHOD}

\begin{abstract}
Acrylamide is a chemical compound found in roasted coffe at temperature above $120^{\circ} \mathrm{C}$. potential to couse cancer in humans. The coffee used by processed at home in the village of Betara sub-district, Tanjung Jabung Barat, Kuala Tungkal, Jambi. The purpose of this study is to compare acrylamide content traditional coffee powder with the high performance liquid chromatography method (HPLC). The phase of motion used acetonitril : phosphate acid (80:20 v/v), using C18 or oktadesil silica (ODS) with size $250 \mathrm{~nm} \times 4,6$ mm,injection volume $20 \mu \mathrm{l}$, detector genesys 10S UV-Vis at wavelength $203 \mathrm{~nm}$. Acrylamide is ground coffee was identified at retention time $(\mathrm{tR}) \pm 5,825$ minute. This method is proven valid with linearity $\mathrm{y}=20717 \mathrm{x}+$ 28752 , correlation coefficient $(r)=0,998 \%$, the limit of detection $0,32109 \mathrm{ppm}$ and the limit of quantitation $1,07031 \mathrm{ppm}$, orecision with $<2 \%$. Acrylamide levels in coffee powder 1 to 4 respectively are $72,065 \mu \mathrm{g} / \mathrm{g}$ sample (1), 66,922 $\mu \mathrm{g} / \mathrm{g}$ sample (2), 60,215 $\mu \mathrm{g} / \mathrm{g}$ sample (3), and $61,422 \mu \mathrm{g} / \mathrm{g}$ sample (4). The four coffee samples showed that the acrylamide levels of each sample exceeded the safe limit of consumption of acrylamide released by FDA is $2 \mu \mathrm{g} / \mathrm{g}$.
\end{abstract}

Key words: Acrylamide, cancer, coffee powder, HPLC 


\section{PENDAHULUAN}

Akrilamida ialah senyawa yang bersifat toksik dalam bentuk monomer, sedangkan senyawa poliakrilamida yang berupa polimernya tidak lagi bersifat toksik (Butue et al., 2019). World Health Organization (WHO) menyatakan bahwa rata-rata asupan akrilamida melalui makanan berada pada rentang $0,3-0,8 \mu \mathrm{g} / \mathrm{kg}$ $\mathrm{BB} /$ hari. Akrilamida yang terdapat pada makanan bukan karena cemaran dari luar, tetapi bisa disebabkan oleh pemanasan asam amino dan gula yang terdapat pada makanan yang bersuhu tinggi (Butue et al., 2019). Menurut Swedish National Food Administration, akrilamida banyak terdapat pada makanan yang berkarbohidrat tinggi yang menggunakan pemanasan dengan suhu tinggi (di atas $120^{\circ} \mathrm{C}$ ). Makanan seperti biskuit, sereal , kentang goreng, popcorn, makanan bayi dan kopi dalam proses pengolahannya menggunakan suhu tinggi (Prabowo et al., 2016). Office of Environmental Health Hazard Assesment (OEHHA), salah satu divisi EPA yang berlokasi di California, Amerika Serikat telah menetapkan bahwa $0,2 \mu \mathrm{g} / \mathrm{hari}$ akrilamida tidak bersifat sebagai agen pencetus kanker (Hermanto dan Adawiyah, 2010).

Masyarakat negara Indonesia melakukan kegiatan meminum kopi sebanyak 3-5 gelas kopi per hari yang di minum pada pagi hari, siang hari, dan malam hari karena kerja lembur atau yang lainnya (Welkriana et al., 2017). Kopi bubuk dibuat dari biji kopi yang disangrai dan kemudian digiling, dan tanpa mengurangi rasa dan aroma dari kopi tersebut serta aman bagi kesehatan (Asra et $a l .$, 2018). Kopi Tungkal merupakan kopi yang banyak diminati oleh masyarakat karena memiliki cita rasa yang khas. Produksi dan prospek pasar kopi liberika merupakan salah satu komoditas unggulan provinsi Jambi yang lebih dikenal dengan sebutan Libtukom (Liberika Tungkal Komposit). Hal ini menjadikan provinsi Jambi sebagai penghasil terbesar jenis kopi liberika di Indonesia dan menjadi lahan suboptimal penuh dengan tanaman kopi Libtukom (Suharyon et al., 2019).

Metode analisis akrilamida telah banyak diteliti menggunakan metode Kromatografi Cair Kinerja Tinggi (KCKT) dan kromatografi gas (Prabowo et al., 2016). Kromatografi Cair Kinerja Tinggi (KCKT) salah satu metode kromatografi yang di dasarkan pada perbedaan distribusi molekul komponen diantara dua fasa (fasa gerak dan fasa diam) yang berbeda kepolarannya. Metode KCKT ialah suatu metode kromatografi cair-cair yang digunakan untuk keperluan pemisahan, pengindentifikasian, ataupun analisis kuantitatif yang berdasarkan pada pengukuran luas puncak analit pada kromatografi dibandingkan luas area standar (Kusuma dan Rosalina, 2016).

\section{BAHAN DAN METODE}

Bahan yang digunakan dalam penelitian ini adalah serbuk kopi tungkal, akrilamida (C3H5NO), diklorometana $(\mathrm{CH} 2 \mathrm{Cl} 2)(\mathrm{pa})$, methanol $(\mathrm{CH} 3 \mathrm{OH})$, asam fosfat $(\mathrm{H} 3 \mathrm{PO} 4)$, asetonitril $(\mathrm{C} 2 \mathrm{H} 3 \mathrm{~N})$ grade HPLC, Aquabides pro injeksi.

Alat yang di gunakan adalah seperangkat alat kromatografi cairan kinerja tinggi (KCKT) (Shimadzu LC-6AD®), kolom ODS C18 $(250 \times 4,6 \mathrm{~mm})$ (Shimadzu Simpack®), detektor Genesys 10S UV-vis, timbangan analitik (Precisa XB 220A®), laboratory shaker (Orbital Shaker $\left.{ }^{\circledR}\right)$, labu ukur (Iwaki $\left.{ }^{\circledR}\right)$, Erlenmeyer (Iwaki $\left.{ }^{\circledR}\right)$, gelas ukur (Iwaki $\left.{ }^{\circledR}\right)$, membran filter $0,45 \mu \mathrm{m}$, kertas saring dan alat-alat gelas yang menunjang penelitian.

\section{Pengambilan Sampel}

Sampel bubuk kopi liberika. Sampel yang dipilih adalah produk kopi bubuk yang dijual di pasar tradisional tungkal.

\section{Pembuatan Larutan Standar Akrilamida}

25,0 $\mathrm{mg}$ standar ditimbang dan dimasukkan kedalam labu ukur 50,0 ml, dilarutkan dengan fase gerak (asetonitril:air) sampai tanda batas, dikocok hingga homogen (larutan A). 1,0 ml larutan A 
dipipet, dan dimasukan kedalam labu ukur 50,0 ml kemudian ditambahkan dengan fase gerak yang digunakan sampai tanda batas (larutan B). dilarutan B dibuat larutan akrilamida dengan konsentrasi 1,2,4,8, ppm.

\section{Mencari Kondisi Analisis Fase Gerak}

Fase gerak yang digunakan untuk optimasi adalah asetonitril : asam fosfat 0,2\% (70:30 v/v), asetonitril : asam fosfat $0,2 \%(80: 20 \mathrm{v} / \mathrm{v})$ dan asetonitril : asam fosfat $0,2 \% \quad(90: 10)$. Selanjutnya dipilih kondisi yang menberikan harga efisiensi yang tinggi dan waktu retensi yang relatif singkat.

\section{Validasi Metode Analisis}

Tahap validasi metoda meliputi :

a. Pembuatan kurva kalibrasi : larutan standar 1,2,4,8 ppm masing-masing disuntikkan sebanyak $20 \mu \mathrm{l}$ kedalam kolom pada kondisi terpilih. Luas puncak dicatat dan dibuat kurva perbandingan luas puncak dengan konsentrasi larutan.

b. Pengujian batas deteksi dan batas kuantitasi. Batas deteksi dan kuantitasi dihitung secara statistik melalui persamaan regresi linier dari kurva kalibrasi. Nilai pengukuran akan sama dengan nilai $b$ pada garis linier $y=a x+$ b.

c. Uji keterulangan (presisi). Larutan standar 1,2,4,8 ppm disuntikan sebanyak $20 \mu 1$ dalam kolom menggunakan fase gerak dan kondisi alir yang terpilih, diulang sebanyak 5 kali, kemudian dicatat luas puncaknya dan dihitung koefisien variasinya.

\section{Penetapan Kadar Akrilamida Dalam Kopi}

Sampel bubuk kopi yang sudah halus ditimbang sebanyak 1 gram kemudian dilarutkan dalam $10 \mathrm{~mL}$ diklormetan, dikocok dan disentrifus lalu ampas disaring (larutan A). Ampas diekstraksi sebanyak 2 kali dengan diklorometan $3 \mathrm{ml}$, disaring (larutan B). Larutan A dan larutan B digabung dan ditambahkan Asetonitril ad 25 ml didalam labu ukur. Larutan diinjeksi kedalam kolom HPLC sebanyak $20 \mu$, kemudian dicatat luas puncaknya. Percobaan diulang sebanyak 3 kali.

\section{HASIL DAN PEMBAHASAN}

Berdasarkan penelitian yang di lakukan dari keempat sampel kopi bubuk Tungkal yang digunakan merupakan hasil olahan rumahan di Desa Kecamatan Betara Kabupaten Tanjung Jabung Barat, Kuala Tungkal, Jambi. Pada penelitian ini fase diamnya menggunakan kolom $\mathrm{C} 18$ atau oktadesil silika (ODS) dengan ukuran 250 $\mathrm{nm} \times$ 4,6 $\mathrm{mm}$. Dimana fase diam mampu memisahkan senyawa-senyawa dengan kepolaran yang rendah, sedang, maupun tinggi dan dapat digunakan pada fase gerak polar dan non polar.

Fase yang gunakan yaitu fase terbalik, dikarenakan senyawa yang digunakan yaitu akrilamida bersifat polar sehingga kolom yang digunakan harus polar juga agar penarikkannya optimal. Fase gerak yang digunakan asetonitril dan asam fosfat $0,2 \%$ dengan perbandingan (80:20), berdasarkan uji panjang gelombang akrilamida didapatkan hasil panjang gelombang $203 \mathrm{~nm}$ menggunakan detektor Genesys 10S UVVis.

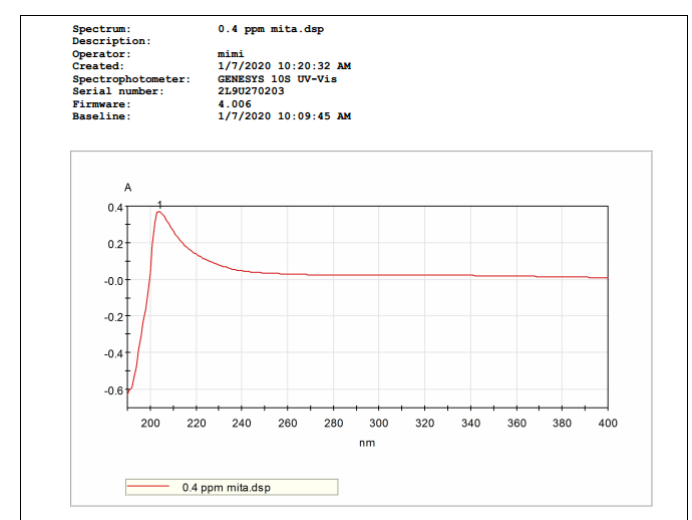

Gambar 1. Hasil spektro larutan standar akrilamida diperoleh panjang gelombang $203 \mathrm{~nm}$

Kurva kalibrasi merupakan hubungan antara luas puncak zat dengan konsentrasi analit yang diketahui. Dari data yang diperoleh dilakukan perhitungan regresi linier dan dihasilkan persamaan garis kurva 
kalibrasi $\mathrm{y}=20717 \mathrm{x}+28752$, dimana $\mathrm{x}$ merupakan konsentrasi akrilamida dan $\mathrm{y}$ merupakan perbandingan luas puncak akrilamida.

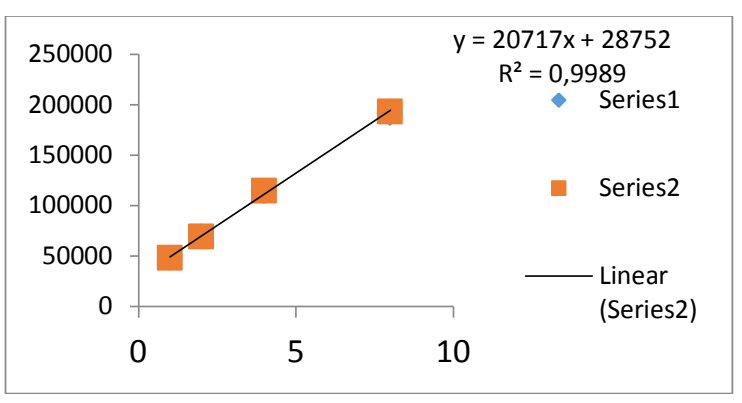

Gambar 2. Grafik kurva kalibrasi akrilamida

Menurut Swedish National Food Administration, akrilamida banyak terdapat pada makanan yang berkarbohidrat tinggi yang menggunakan pemanasan dengan suhu tinggi (di atas $120^{\circ} \mathrm{C}$ ). Pemanasan suhu tinggi tersebut seperti biskuit, sereal , kentang goreng, popcorn, makanan bayi dan kopi dalam (Prabowo et al., 2016).

Pada penelitian ini menggunakan validasi metoda KCKT dari senyawa akrilamida dilakukan terhadap beberapa parameter yaitu linieritas, LOD dan LOQ, akurasi dan presisi. Sebenarnya, telah banyak metode yang dikembangkan oleh penelitian mancanegara,seperti kromatografi gas, kromatografi gas spektrofotometri massa, dan kromatografi cair spektrofotometri massa (Nugraheni dan Anggoro, 2016).

Pada limit of detection (LOD) dan limit of quantitaton (LOQ) ditentukan dari persamaan regresi linier kurva kalibrasi. LOD ditentukan untuk mengetahui konsetrasi analit terendah yang dapat diukur, limit deteksi metode ini adalah 0,32109 $\mu \mathrm{g} / \mathrm{ml}$, LOQ ditentukan untuk mengetahui konsentrasi terendah yang dapat ditentukan oleh suatu metode pada tingkat ketelitian dan ketepatan yang baik, didapatkan nilai LOQ berdasarkan hasil uji adalah 1,07031 $\mu \mathrm{g} / \mathrm{ml}$.

Uji presisi dilakukan untuk uji kesesuaian sistem yang dilakukan setelah melakukan KCKT. Uji ini dilakukan dengan menyuntikkan berulang larutan standar akrilamida yang diketahui konsentrasinya untuk menentukan kinerja alat pada kondisi dengan batas presisi RSD $\leq 2 \%$. Ketelitian metode dilakukan sebanyak 3 kali pengulangan.

Dari hasil analisis diketahui bahwa kadar akrilamida pada sampel kopi tungkal I sebesar 72,065 $\mu \mathrm{g} / \mathrm{g}$, sampel kopi tungkal II sebesar 66,922 $\mu \mathrm{g} / \mathrm{g}$, sampel kopi tungkal III sebesar $60,215 \mu \mathrm{g} / \mathrm{g}$ dan sampel kopi tungkal IV yang itu kopi pembanding sebesar $61,422 \mu \mathrm{g} / \mathrm{g}$.

Table 1. Hasil penetapan kadar akrilamida pada kopi

\begin{tabular}{ccc}
\hline Sampel & $\begin{array}{c}\text { Larutan uji } \\
(\boldsymbol{\mu g} / \mathbf{m l})\end{array}$ & $\begin{array}{c}\text { Kadar } \\
\text { sampel } \\
(\boldsymbol{\mu g} / \mathbf{g})\end{array}$ \\
\hline Kopi 1 & 2,8826 & 72,065 \\
Kopi 2 & 2,6769 & 66,922 \\
Kopi 3 & 2,4086 & 60,215 \\
Kopi 4 & 2,4569 & 61,422 \\
\hline
\end{tabular}

Umumnya seorang meminum kopi sebanyak 1-3 cangkir perhari, jika berat dalam kopi bubuk 1 sendok 5 gram, maka kadar akrilamida dalam satu cangkir kopi berkisar antara 640-7305 $\mu$ g (Fuferti.Z et al 2013). Berdasarkan data tersebut, maka kadar akrilamida yang diperoleh dari keempat sampel dikatakan sangat tidak aman untuk dikonsumsi hingga $15 \mathrm{~g}$ dalam sehari (1920-21915 $\mu \mathrm{g})$ pada orang dewasa berdasarkan World Health Organization (WHO) tahun 2002. Kopi tungkal cara pengolahannya masih menggunakan cara tradisional dimana kopi masih disangrai dengan tungku tanpa diketahui temperaturnya, sehingga kopi tungkal memiliki kadar akrilamida yang tinggi.

\section{KESIMPULAN}

Metode Kromatografi Cair Kinerja Tinggi (KCKT) dalam menganalisis akrilamida dalam kopi bubuk tungkal memberi kondisi optimum dengan kolom fase terbalik C18 dengan panjang kolom 250 
$\mathrm{mm}$, diameter 4,6 mm, volume injeksi $20 \mu \mathrm{l}$, kecepatan alir $0,5 \mathrm{ml} / \mathrm{menit}$, fase gerak asetonitril : asam fosfat $0,2 \%$ (80:20), detektor Genesys 10S UV-vis dengan panjang gelombang $203 \mathrm{~nm}$ dengan uji validasi : LOD dan LOQ, uji presisi, uji batas deteksi dan batas kuantitasi. Maka Dari keempat sampel kopi Tungkal yang di uji mengandung akrilamida di atas ambang batas aman menurut Food and Drugs Adminitration (FDA) yaitu $2 \mu \mathrm{g} / \mathrm{g}$.

\section{DAFTAR PUSTAKA}

Asra, Ridho, Rusdi, Sofia Nofianti, and Nessa Nesaa. (2018). Perbandingan Akrilamidakopi Bubuk Tradisional Dan Luwak Dengan Metode HPLC. Jurnal Katalisator 3(2):153-61.

Butue, Leobernard, Fatimawali, and Defny S. Wewengkang. (2019). Penetapan Kadar Akrilamida Pada Kentang Goreng Yang Beredar Di Restoran Cepat Saji Di Kota Manado Dengan Menggunakan Spektrofotometri UvVis. Pharmacon Jurnal Ilmiah Farmasi 8(3):198-204.

FAO Dan WHO. (2002). Health Implications Of Acrylamide In Food: Report Of A Joint FAO/WHO Consultation; 2002: Jun 25-27; Geneva, Switzerland.WHO Headquarters: 1213.

Fuferti.Z, Megah Aysah, Syakbaniah, and Ratnawulan. (2013). Perbandingan Karakteristik Fisis Kopi Luwak ( Civet Coffee ) Dan Kopi Biasa Jenis Arabika. Pillar of Physics 2(1):68-75.

Hermanto, Sandra and Robiatul Adawiyah. (2010). Analisis Kadar Akrilamida Dalam Sediaan Roti Kering Secara KCKT. Jurnal Kimia VALENSI 2(1):354-61.

Kusuma, Arif Satria Wira and Gabriella Rosalina. (2016). Analisis Kadar Kapsiasin Dari Ekstrak 'Bon Cabe' Dengan Menggunakan Kromatografi Cair Kinerja Tinggi (KCKT). Farmaka 14(2):11-18.

Nugraheni, B. and A. B. Anggoro. (2016). Validasi Metode Analisis
Ciprofloksasin Menggunakan High Performance Loquid Chromatography. Inovasi Teknik Kimia 1(1):6-8.

Prabowo, M.Hatta, Ari Wibowo, and Fitri Yuliani. (2016). Identifikasi Dan Analisis Akrilamida Dalam Kopi Serbuk (Tubruk) Dan Kopi Instan Dengan Metode Kromatografi Cair Kinerja Tinggi. Ijurnal Ilmiah Farmasi 9(1):1-12.

Suharyon, Busyra, and BS. (2019). Potensi, Kendala Dan Prospek Pengembangan Kopi Liberika: Studi Kasus Petani Kopi Liberika Kelurahan Mekar Jaya Kabupaten Tanjung Jabung Barat Jambi. Jurnal Ilmiah Ilmu Terapan Universitas Jambi 3 (2011):93-99.

Welkriana, Putri Widelia, Halimah Halimah, and Ahmat Redyansya Putra. (2017). Pengaruh Frekuensi Minum Kopi Terhadap Kadar Asam Urat Darah. Bioedukasi (Jurnal Pendidikan Biologi) 8(1):83. 